\title{
Oral surgery — a study of referral by GDPs
}

\author{
Referral patterns and the referral system for oral surgery care. Part 1: General dental practitioner referral patterns \\ by P. Coulthard, I. Kazakou, R. Koron, and H. V. Worthington Br Dent J 2000; 188: 142-145
}

\section{Objective}

To investigate current GDP oral surgery referral patterns given the anticipated change since the introduction by the General Dental Council of the specialty of surgical dentistry.

\section{Design}

Postal questionnaire.

\section{Setting}

400 GDPs in Greater Manchester.

\section{Results}

$84 \%$ participation rate. $69 \%$ of dentists made a referral because of anticipated difficulty of surgery and $49 \%$ because of the complex nature of the patients' medical history. Practitioners who had undergone some oral surgery postgraduate training were more likely to undertake more surgery in their practices $(P<0.01)$ and to refer more patients for specialist care $(P<0.05)$. While female practitioners rated their own surgical confidence less highly than male practitioners $(P<0.001)$, and younger practitioners less than their older colleagues $(P<0.05)$, there was no significant difference in the number of referrals made.

\section{Conclusion}

The most common reasons for referral were the anticipated difficulty of surgery and patient medical compromise. There was a wide variation between practitioners in the number of patients referred for specialist care. Postgraduate oral surgery training was identified as a factor contributing to this variation. Other practitioner variables, such as sex, experience and type of practice were not found to contribute.

\section{In brief}

- This study reports the wide variation in the number of patients referred for specialist care by general dental practitioners.

- Practitioners who had undergone some postgraduate training in oral surgery were more likely to undertake more surgery in their practice but were also more likely to refer more patients for specialist care.

- While female practitioners rated their own surgical confidence less highly than male practitioners and younger practitioners less than their older colleagues, there was no significant difference in the number of referrals made.

\section{Comment}

Coulthard et al. have produced an interesting and relevant report on current delivery of specialist oral and maxillofacial surgery services. In essence, the researchers undertook a postal survey of 400 general dental practitioners in the Greater Manchester area to determine the reasons that they referred patients to a specialist oral and maxillofacial surgery service. The authors managed to achieve an $84 \%$ response rate, which is very commendable for this type of survey.

The key reasons for referring patients were that the practitioners felt the surgery was likely to be difficult or that it was required for a patient having a complex medical history. The respondents were only given a choice of six possible reasons for referral. It would have been better to allow a free text response and then classify the responses. It is regrettable that a referral to enable a diagnostic decision was not included (for example, whether to remove a particular third molar). It was also interesting that general dental practitioners with some oral surgery exposure (as hospital trainees, for example) better provided more oral surgery within their practices and referred more cases suggesting that a greater proportion of their patients were perceived as requiring oral surgery. This might be interpreted in two ways: the practitioners may either have identified additional disease which they then treated or they may have treated a larger number of disease-free cases on a prophylactic basis.

In terms of which specialist centre the practitioner referred their patients to, the decision was made on the basis of an efficient service (for example, short waiting times) and personal trust in the specialist. These key factors should provide interesting food for thought to colleagues con- sidering setting up a specialist referral service.

The message of this paper is clear: general practitioners value specialist oral surgery services because they are able to help the management of complex cases and they select the particular service that they choose to use on the basis of 'old fashioned' values such as trust and service. As we move towards more community-based oral surgery services, with a vibrant practice led sector as well as traditional centres, it will be those units that can deliver on these fronts that will deservedly prosper.

\section{Brickley}

Clinical Lecturer, Department of Oral Surgery, Medicine and Pathology, University of Wales College of Medicine 